\title{
Feasibility of opportunistic screening for type 2 diabetes mellitus: Need for interventions to improve follow up
}

Hemant Deepak Shewade*, Chinnakali Palanivel ${ }^{1 *}$, Kandan Balamurugesan ${ }^{2}$, Ramu Vinayagamoorthi $^{3}$, Bhuvaneswary Sunderamurthy ${ }^{4}$, Kavita Vasudevan ${ }^{4}$, Sharbari Basu' ${ }^{3}$, Narayana Rajagopalan ${ }^{5}$

Department of Community Medicine, Mahatma Gandhi Institute of Medical Sciences, Sevagram, Wardha, ${ }^{1}$ Department of Preventive and Social Medicine, Jawaharlal Institute of Postgraduate Medical Education and Research, Puducherry, ${ }^{2}$ Departments of Medicine, ${ }^{3}$ Biochemistry, ${ }^{4}$ Community Medicine, Indira Gandhi Medical College and Research Institute, a Government of Puducherry Institute, ${ }^{5}$ Department of Orthopaedics, Raja Rajeswari Medical College and Hospital, Bangalore, Karnataka, India

\section{A B S T R A C T}

Objective: To determine the feasibility of opportunistic screening for type 2 diabetes (T2DM) among adult attendees of medicine outpatient department (OPD) at a tertiary care hospital in Puducherry district, India. Materials and Methods: A hospital-based cross-sectional study was conducted among nonpregnant nondiabetic adults above 30 years of age attending MOPD to screen for diabetes mellitus (DM). Those with random blood glucose of $6.1 \mathrm{mM} / \mathrm{l}$ or more were sent for definitive tests; fasting plasma glucose and post prandial (PP) plasma glucose. Double data entry and validation was done. Results: A total of 510 outpatients were tested for random blood glucose: 278 (54.5\%) had blood glucose above the cut off. Out of 278, 83 (29.9\%) returned for definitive tests: 18 [2।.7\%, $0.95 \mathrm{Cl}$ : I4.2\%, $31.7 \%$ ] had either fasting plasma glucose and/or PP plasma glucose in diabetic range and 16 (19.3\%, $0.95 \mathrm{Cl}:$ I2.2\%, 29.1\%) had impaired fasting glucose and/or impaired glucose tolerance. Case detection (screening yield) of diabetes in the adult outpatients was $3.5 \%(0.95 \mathrm{Cl}: 2.2 \%$, 5.5\%). Conclusion: Compliance or follow-up for definitive tests was poor resulting in low screening yield. Future studies should focus on interventions to improve follow up of outpatients.

Key words: Adult, blood glucose, cross-sectional study, diabetes mellitus, early diagnosis, India, outpatients, screening, tertiary care center, type 2

\section{INTRODUCTION}

Diabetes mellitus (DM) which is a major risk factor for chronic disease on its own causes increased death and disability. In developed and developing countries, approximately $50-70 \%$ of diabetes remains undiagnosed. ${ }^{[1,2]}$

\begin{tabular}{|l|l|}
\hline \multicolumn{2}{|c|}{ Access this article online } \\
\hline Quick Response Code: & Website: \\
\hline & www.josh.net \\
\cline { 2 - 2 } & \\
\hline
\end{tabular}

Screening for diabetes and pre-diabetes among adults may be cost saving. ${ }^{[3]}$ Opportunistic screening in routine practice may be an affordable alternative or adjunct to population screening. ${ }^{[4,5]}$ Cost effectiveness for diabetic screening increases when done opportunistically and by risk assessment before glucose testing ${ }^{[6]}$ A systematic review has identified that opportunistic screening for diabetes among 45-54 years African Americans is highly cost effective. ${ }^{[7]}$ Few studies from the west have documented the feasibility of opportunistic screening for diabetes, ${ }^{[8,9]}$ but none from India which has a large burden of diabetes. According to the diabetes atlas published by the International Diabetes Federation, the number of people with diabetes in India is around 65 million (2013) and is expected to rise to 101.2 million by 2030 , unless urgent

*Hemant Deepak Shewade and Chinnakali Palanivel as 'shared first authors'. Both had equally contributed to the research work.

Corresponding Author: Dr. Hemant Deepak Shewade, Department of Community Medicine, Mahatma Gandhi Institute of Medical Sciences, Sevagram, Wardha - 442 102, Maharashtra, India. E-mail: hemantjipmer@gmail.com 
preventive steps are taken. ${ }^{[10]}$ To contain the increasing burden of Non-Communicable Diseases (NCDs), Ministry of Health and Family welfare, Government of India, has launched the National Program on Prevention and Control of Diabetes, Cardiovascular diseases and Stroke (NPDCS). ${ }^{[1]}$ The national program is still in expansion phase and has not yet been implemented in Puducherry. One of the strategies of the program, opportunistic screening of persons above 30 years, can be field tested before implementation. This study was carried out to assess the feasibility of opportunistic screening for type 2 diabetes (T2DM) among outpatients attending medicine outpatient department (OPD) at a tertiary care center in Puducherry district, India.

\section{MATERIALS ANd Methods}

\section{Study design and setting}

A facility-based cross-sectional study was carried out in Indira Gandhi Medical College and Research Institute (IGMCRI) of Puducherry, which caters to an average of 1000 outpatients per day. On an average, medicine department handles about 200-250 outpatients per day. There is no existing screening program for any NCD in the study facility and in the Puducherry district as well. No representative survey was carried out to document the prevalence of T2DM in Puducherry. Smaller studies have reported prevalence ranging from $5.8-9 \% \cdot{ }^{[12-15]}$ These studies have estimated prevalence using different definitions/cut offs and varied age groups (above 20 years and 25 years).

\section{Study/eligible population}

All nonpregnant nondiabetic outpatients (age above 30 years) attending medicine OPD constituted the eligible population. Outpatients who were known diabetic were excluded. The study period, including protocol development, data collection, data entry and analysis was four months, December 2012 to March 2013.

\section{Sample size and sampling}

Assuming a prevalence of T2DM as 10\% among outpatients; an alpha value of 0.05 with absolute precision of $\pm 3 \%$ and a drop out of $20 \%$, a total of 456 outpatients were required for the study. Expecting a drop out in outpatients referred for fasting plasma glucose (FPG) and post prandial plasma glucose (PPPG), a dropout of $20 \%$ was factored in while calculating sample size. Outpatients who gave their consent were included and the study was carried for 6 OPD days till the desired sample size was attained.

\section{Procedure}

All eligible outpatients attending medicine OPD were offered random blood glucose (RBG) test. RBG testing of capillary blood sample was done using a glucometer (One Touch SelectSimple Glucose Meter). Glucometer was standardized every morning against a standard glucose solution. Out patients above 30 years of age having RBG values $6.1 \mathrm{mM} / 1$ or above (screening criteria) were asked to undergo definitive tests, FPG and PPPG, for the diagnosis of diabetes next day morning. FPG and PPPG testing of venous blood sample was done using a fully automated blood chemistry analyzer by glucose oxidase method. RBG cut off of $6.1 \mathrm{mM} / 1$ was based on a study carried out in Chennai, India, which recommended this cut off value for the definitive tests for diabetes and pre-diabetes in Asian Indians. ${ }^{[16]}$ For epidemiological diagnosis, a FPG value of $7 \mathrm{mM} / 1$ or more and/or a PPPG value of $11.1 \mathrm{mM} / 1$ or more was considered as diabetes mellitus. FPG between 6.1 and $6.9 \mathrm{mM} / 1$; and/or PPPG between 7.8 and $11 \mathrm{mM} / 1$ was considered as pre-diabetes. ${ }^{[17,18]}$

Data entry and analysis

Data collected was double entered and validated in EpiData v.3.1 software. Analysis was carried out using EpiData analysis v.2.2.178 software. Proportions and 95\% confidence intervals (CI) were calculated. Key analytical outputs were: (i) Proportion (number) of outpatients above 30 years of age (and not known diabetic); (ii) Proportion (number) of outpatients who got their RBG tested; (iii) Proportion (number) of outpatients whose RBG was above or equal to $6.1 \mathrm{mM} / \mathrm{l}$; (iv) Proportion (number) of outpatients with RBG above or equal to $6.1 \mathrm{mM} / 1$ who returned for definitive tests; (v) Proportion (number) of outpatients with RBG above or equal to $6.1 \mathrm{mM} / 1$ who had FPG $7 \mathrm{mM} / 1$ or above (diabetes) or between 6.1 and $6.9 \mathrm{mM} / \mathrm{l}$ (pre-diabetes); and (vi) Proportion (number) of outpatients with RBG above or equal to6. $1 \mathrm{mM} / 1$ who had fasting plasma glucose $7 \mathrm{mM} / 1$ or above (diabetes) or between 6.1 and $6.9 \mathrm{mM} / 1$ (pre-diabetes).

\section{Ethics considerations}

The study was approved by the Institute Ethics Committee. Patient information sheet and consent form were prepared both in English and in the local language (Tamil). Study participants found to be diabetic or pre-diabetic were provided standard care in the hospital. Cash incentives or incentives of any other form were not given to study participants.

\section{RESULTS}

Patient load in medicine OPD during 6 days of study was 2170: out of which 1723 were more than 30 years of age; and 355 were known cases of DM. Prevalence of diabetes among nonpregnant outpatients more than 30 years 
was $20.6 \%$. Patient load of nonpregnant nondiabetic outpatients (more than 30 years) attending medicine OPD during the same period was 1368 . This was $63 \%$ of total medicine outpatient load. Of them, 510 outpatients (37.3\%) gave consent and were screened. Their mean age was 47.4 years $(\mathrm{SD}=11.7$ years) and $66.7 \%$ of them were females. Mean RBG was $7 \mathrm{mM} / 1$ (SD-2.8 mM/l).

Out of 510,278 (54.5\%) had RBG greater than or equal to $6.1 \mathrm{mM} / 1$. Of 278 outpatients, 83 (29.9\%) returned for definitive tests: FPG and PPPG [Figure 1]. Of the 83 outpatients, 18 [21.7\%, 0.95 CI: 14.2\%, 31.7\%] had either fasting plasma glucose and/or PPPG in diabetic range and 16 (19.3\%, $0.95 \mathrm{CI}: 12.2 \%, 29.1 \%)$ had impaired fasting glucose and/or impaired glucose tolerance (prediabetes). Test wise analysis showed that 14 (16.9\%) had FPG in the diabetic range, $6(7.2 \%)$ had impaired fasting glucose; and 16 (19.3\%) had PPPG in the diabetic range, $15(18.1 \%)$ had impaired glucose tolerance [Table 1]. Case detection in the sample of adult outpatients more than 30 years was $3.5 \%$ (0.95 CI: $2.2 \%, 5.5 \%)$. There was no clinically significant difference in age, sex and RBG

\begin{tabular}{|c|c|c|c|c|}
\hline \multicolumn{5}{|c|}{$\begin{array}{l}\text { Table 1: Cross-tabulation of fasting plasma glucose (FPG) } \\
\text { and post prandial plasma glucose (PPPG) results among } \\
\text { outpatients with } \mathrm{RBG}>/=6.1 \mathrm{mM} / \mathrm{l}(n=83)\end{array}$} \\
\hline $\begin{array}{l}\text { Results of definitive } \\
\text { tests }\end{array}$ & $\begin{array}{l}\text { PPPG } \\
\text { normal }\end{array}$ & $\begin{array}{l}\text { Impaired } \\
\text { glucose } \\
\text { tolerance }\end{array}$ & $\begin{array}{l}\text { PPPG } \\
\text { diabetic } \\
\text { range }\end{array}$ & Total \\
\hline FPG normal & 49 & 12 & 2 & 63 \\
\hline Impaired fasting glucose & 3 & 1 & 2 & 6 \\
\hline FPG diabetic range & 0 & 2 & 12 & 14 \\
\hline Total & 52 & 15 & 16 & 83 \\
\hline
\end{tabular}

FPG $=$ Fasting plasma glucose; $P P P G=$ Post prandial plasma glucose

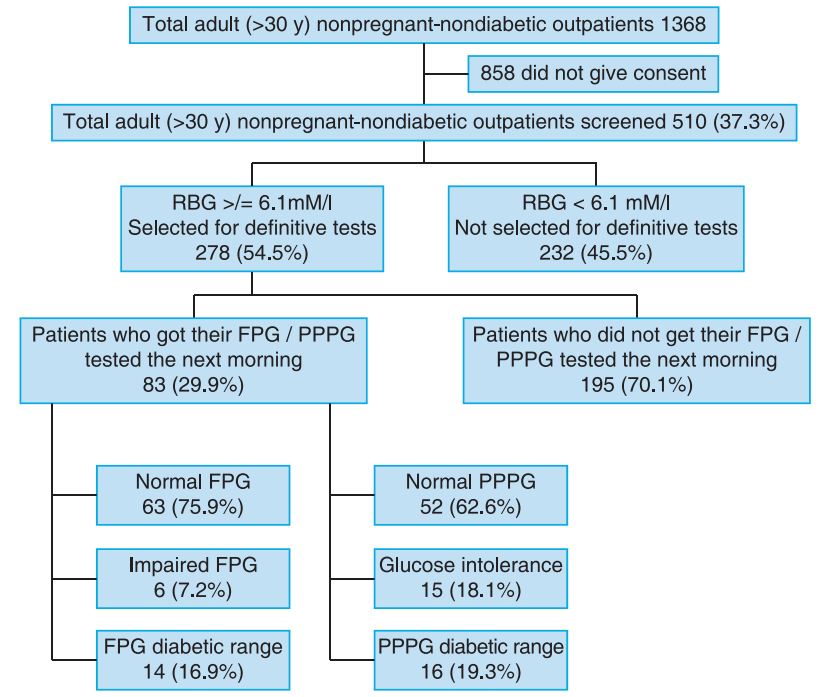

Figure 1: Flow chart depicting feasibility of opportunistic screening for Diabetes mellitus among OPD adult ( $>30 \mathrm{y}$ ) nonpregnant outpatients in a tertiary care setting distribution among compliant $(\mathrm{RBG}>/=6.1 \mathrm{mM} / 1$ and got tested for FPG/PPPG) and non-compliant outpatients $(\mathrm{RBG}>/=6.1 \mathrm{mM} / 1$ and did not get tested for FPG/ PPPG).

\section{DISCUSSION}

This study had used RBG greater than or equal to 6.1 $\mathrm{mM} / 1$ and age more than 30 years as initial screening criteria before definitive tests for DM. Compliance for definitive tests was poor (29.9\%). Among compliant outpatients, $21.7 \%$ had plasma glucose in diabetic range. If the compliance for definitive tests had been 100\%, 60 outpatients would have been detected to have FPG/PPPG in diabetic range. We missed out on 42 of them. This resulted in a low screening yield of $3.5 \%$ among all adult (more than 30 years) nonpregnant outpatients (number needed to screen: 29). Maximum possible screening yield would have been $11.8 \%$ if there was $100 \%$ compliance for definitive tests (number needed to screen: 9).

A study on the profile of newly diagnosed diabetes patients from Chennai, India, showed that approx. 70\% diagnoses were coincidental. ${ }^{[5]}$ This further indicates the need for opportunistic screening of DM among outpatients attending clinics. As done in this study, there is also a need to identify outpatients with impaired fasting and glucose tolerance with the aim of preventing future diabetes. ${ }^{[19]}$

The reason for low screening yield could be the need to go for definitive test next morning. Drop-out was more than expected. It is quite possible that outpatients with higher knowledge and positive attitude towards DM might have come the next day. This being a tertiary care setting, with no defined service delivery population unlike a primary care setting, follow up was an issue. Even evaluation of diabetes screening in west has shown that there is low screening yield in diabetes screening: main reason being poor follow up of outpatients. ${ }^{[8]}$ Screening criteria to be used before the definitive tests can be modified depending on the setting: standard screening guidelines can be prepared accordingly. In a high volume setting (high OPD load), the age cut off can be increased to 45 years. Another option is to use Indian Diabetes Risk Score as a screening test. ${ }^{[20]}$ In younger outpatients (less than 30 years), Indian Council of Medical Research (ICMR) screening guidelines can be used. ${ }^{[18]}$ Definitive tests used in this study (FPG/PPPG) can be replaced with HbA1C testing depending on the availability of a standard laboratory, with a caution that $\mathrm{HbA1C}$ detects more cases of diabetes than the usual FPG/PPPG. ${ }^{[21]} \mathrm{HbA1C}$ also has the additional advantage of not requiring a fasting sample; 
blood can be collected the same day thus improving follow up. For epidemiological diagnosis, we have used single diagnostic criteria rather than the diagnostic criteria for diabetes which is (presence of any one): Elevated FPG $(>/=$ $7 \mathrm{mM} / \mathrm{l})$ and elevated PPPG $(>/=11.1 \mathrm{mM} / \mathrm{l})$; or if only one is elevated then an elevated value on repeat of the same test; or any one elevated with symptoms of polyuria, polyphagia, and polydipsia.

This is first such study from the region assessing the feasibility of opportunistic screening of diabetes among adult outpatients. Double data entry and validation ensured quality data. The intervention of offering a screening test benefitted the outpatients. This helped in early diagnosis of diabetes or pre-diabetes in some of the participants. This project was carried out with existing manpower and other resources in the hospital which is important to implement the opportunistic screening in real life resource limited settings in developing countries.

The study participants were recruited from medicine OPD alone and it can introduce selection bias. Characteristics may be different for outpatients attending medicine OPD and other OPDs. RBG testing has its own limitations. False positives and false negatives regarding diagnosis of diabetes will be there because of sensitivity and specificity of RBG test. However, by reducing the cut off to $6.1 \mathrm{mM} / 1$, false positives and false negatives were reduced to a large extent.

This study further enforces the need for preventive medicine clinics for opportunistic screening of NCDs and their risk factors, not just diabetes. ${ }^{[22]}$ Outpatients' visit to the hospital must be treated as an opportunity for primary and secondary prevention of NCDs. Future studies should focus on interventions to improve follow up of outpatients for definitive tests identified by screening. Mobile technology can be one such mode of intervention. The same may be applied in the national program after appropriate field testing.

\section{CONCLUSION AND RECOMMENDATION}

Compliance/follow up for definitive tests was poor resulting in low screening yield. Future studies should focus on interventions to improve follow-up of outpatients.

\section{ACKNOWLEDGEMENT}

We would like to thank Prof KC Panigrahi, Head, Department of Community Medicine, IGMCRI Puducherry, for his guidance and support.

\section{REFERENCES}

1. Zeitz PS, Harrison LH, Lopez M, Cornale G. Community health worker competency in managing acute respiratory infection of childhood in Bolivia. Bull Pan Am Health Organ 1993;27:109-19.

2. Mohan V, Deepa M, Deepa R, Shanthirani CS, Farooq S, Ganesan $A$, et al. Secular trends in the prevalence of diabetes and impaired glucose tolerance in urban South India - the Chennai Urban Rural Epidemiology Study (CURES-17). Diabetologia [Internet]. 2006;49:1175-8. Available from: http://www.ncbi.nlm.nih.gov/ pubmed/16570158 [Last accessed on 2013 Dec 3].

3. Chatterjee R, Narayan KM, Lipscomb J, Phillips LS. Screening adults for pre-diabetes and diabetes may be cost-saving. Diabetes Care [Internet]. 2010;33:1484-90. Available from: http://www. pubmedcentral.nih.gov/articlerender.fcgi?artid=2890345\&tool $=$ pmcentrez\&rendertype $=$ abstract [Last accessed on 2013 Dec 3]

4. Pereira Gray DJ, Evans PH, Wright C, Langley P. The cost of diagnosing Type 2 diabetes mellitus by clinical opportunistic screening in general practice. Diabet Med [Internet]. 2012;29:863-8. Available from: http://www.ncbi.nlm.nih.gov/ pubmed/22313143 [Last accessed 2013 Dec 3].

5. Ramachandran A, Snehalatha C, Vijay V, Colagiuri S. Detecting undiagnosed diabetes in urban Asian Indians--role of opportunistic screening. J Assoc India [Internet]. 2004 Jul 52:545-6. Available from: http://www.ncbi.nlm.nih.gov/pubmed/15645978 [Last accessed on 2013 Nov 25].

6. Klein Woolthuis EP, De Grauw WJ, Van Weel C. Opportunistic screening for type 2 diabetes in primary care. Lancet [Internet]. 2010;376:683-4. Available from: http://www.thelancet.com/ journals/a/article/PIIS0140-6736\%2810\%2961332-3/fulltext [Last accessed on 2013 Dec 3].

7. Li R, Zhang P, Barker LE, Chowdhury FM, Zhang X. Costeffectiveness of interventions to prevent and control diabetes mellitus: A systematic review. Diabetes Care [Internet]. 2010;33:1872-94. Available from: http://www.pubmedcentral.nih. gov/articlerender.fcgi?artid $=2909081$ \&tool $=$ pmcentrez\&rendert ype $=$ abstract [Last accessed on 2013 Nov 14].

8. Ealovega MW, Tabaei BP, Brandle M, Burke R, Herman WH. Opportunistic screening for diabetes in routine clinical practice. Diabetes Care [Internet]. 2004;27:9-12. Available from: http:// www.ncbi.nlm.nih.gov/pubmed/14693958 [Last accessed on 2013 Nov 25].

9. Klein Woolthuis EP, De Grauw WJ, van Gerwen WH, van den Hoogen HJ, van de Lisdonk EH, Metsemakers JF, et al. Yield of opportunistic targeted screening for type 2 diabetes in primary care: The diabscreen study. Ann Fam Med [Internet] 2009;7:422-30. Available from: http://www.pubmedcentral.nih. gov/articlerender.fcgi?artid $=2746521$ \&tool $=$ pmcentrez\&render type $=$ abstract [Last accessed on 2013 Dec 3].

10. Diabetes Atlas | International Diabetes Federation [Internet]. 2013. Available from: http://www.idf.org/diabetesatlas [Last accessed on 2013 Nov 22].

11. Operational guidelines. National programme for prevention and control of cancer, diabetes, cardiovascular disease and stroke (NPCDCS). Directorate General of Health Services, Ministry of Health \& Family Welfare. Government of India. [Internet]. 2011. Available from: http://health.bih.nic.in/Docs/Guidelines/ Guidelines-NPCDCS.pdf [Last accessed on 2013 Nov 22].

12. Bharati DR, Pal R, Kar S, Rekha R, Yamuna TV, Basu M. Prevalence and determinants of diabetes mellitus in Puducherry, South India. J Pharm Bioallied Sci [Internet] 2011;3:513-8. Available from: http://www.ncbi.nlm.nih.gov/entrez/query.fcgi?cmd=Retrieve\&d $\mathrm{b}=$ PubMed\&dopt $=$ Citation\&list_uids $=22219584$ [Last accessed on 2012 Jun 1]. 
13. Gupta SK, Singh Z, Purty AJ, Kar M, Vedapriya D, Mahajan P, et al. Diabetes prevalence and its risk factors in rural area of Tamil Nadu. Indian J Community Med [Internet]. 2010;35:396-9. Available from: http://www.pubmedcentral.nih.gov/articlerender.fc gi ?artid $=2963877 \&$ tool $=$ pmcentrez\&rendertype $=$ abstract [Last accessed 2013 on Nov 22].

14. Gupta SK, Singh Z, Purty AJ, Vishwanathan M. Diabetes prevalence and its risk factors in urban Pondicherry. Int J Diabetes Dev Ctries [Internet] 2009;29:166-9. Available from: http://www. pubmedcentral.nih.gov/articlerender.fcgi?artid $=2839131 \&$ tool $=p$ mcentrez\&rendertype = abstract [Last accessed on 2013 Nov 22]

15. Majgi SM, Soudarssane BM, Roy G, Das AK. Risk factors of diabetes mellitus in rural Puducherry. Online $\mathrm{J}$ Health Allied Sci [Internet] 2012;11:1-7. Available from: http://www.ojhas.org/ issue41/2012-1-4.htm [Last accessed 2013 Nov 23].

16. Somannavar S, Ganesan A, Deepa M, Datta M, Mohan V. Random capillary blood glucose cut points for diabetes and pre-diabetes derived from community-based opportunistic screening in India. Diabetes Care [Internet] 2009;32:641-3. Available from: http:// www.pubmedcentral.nih.gov/articlerender.fcgi?artid $=2660445$ \& tool $=$ pmcentrez\&rendertype $=$ abstract [Last accessed on 2013 Nov 22].

17. Screening for Type 2 Diabetes. Report of a World Health Organization and International Diabetes Federation meeting, 2003. [Internet]. Geneva; 2003. Available from: http://www. who.int/diabetes/publications/en/screening_mnc03.pdf [Last accessed on 2013 Nov 22].

18. Guidelines for Management of Type 2 Diabetes. Indian Council of Medical Research (ICMR). New Delhi, India. [Internet]. 2005. Available from: http://icmr.nic.in/guidelines_diabetes/guide_ diabetes.htm [Last accessed on 2013 Nov 22].

19. Waugh N, Scotland G, McNamee P, Gillett M, Brennan A, Goyder $\mathrm{E}$, et al. Screening for type 2 diabetes: Literature review and economic modelling. Health Technol Assess 2007;11:1-125. Available from: http://www.ncbi.nlm.nih.gov/pubmed/17462167 [Last accessed on 2013 Nov 25].

20. Mohan V, Deepa R, Deepa M, Somannavar S, Datta M. A simplified Indian Diabetes Risk Score for screening for undiagnosed diabetic subjects. J Assoc Physicians India [Internet] 2005;53:759-63. Available from: http://www.ncbi.nlm.nih.gov/pubmed/16334618 [Last accessed on 2013 Nov 25].

21. Nazir A, Papita R, Anbalagan VP, Anjana RM, Deepa M, Mohan V. Prevalence of diabetes in Asian Indians based on glycated hemoglobin and fasting and $2-\mathrm{H}$ post-load $(75-\mathrm{g})$ plasma glucose (CURES-120). Diabetes Technol Ther [Internet] 2012;14:665-8. Available from: http://www.ncbi.nlm.nih.gov/pubmed/22823754 [Last accessed on 2013 Nov 25].

22. Shewade HD, Palanivel C. Preventive medicine clinics in hospitals of India: An opportunity missed. Int J Med Public Health 2013;3:2-4.

How to cite this article: Shewade HD, Palanivel C, Balamurugesan $\mathrm{K}$, Vinayagamoorthi R, Sunderamurthy B, Vasudevan $\mathrm{K}$, et al. Feasibility of opportunistic screening for type 2 diabetes mellitus: Need for interventions to improve follow up. J Soc Health Diabetes 2015;3:43-7.

Source of Support: Nil. Conflict of Interest: None declared. 